\title{
CONTRIBUIÇÃO DA GEOGRAFIA FÍSICA E DA EDUCAÇÃO AMBIENTAL NA PRÁTICA DE PROFESSORES DE GEOGRAFIA A PARTIR DO ESTUDO DE BACIAS HIDROGRÁFICAS EM ÁREAS URBANAS
}

\section{Contribution of Physical Geography and Environmental Education for the practice of Geography Teachers using the study of watersheds in urban areas}

\author{
Anice Afonso \\ Doutoranda em Geografia pelo PPGG/IGEO/UFRJ \\ aniceafonso@gmail.com
}

Artigo recebido em 29/01/2013 e aceito para publicação em 01/06/2013

DOI: 10.12957/tamoios.2013.4874

RESUMO A integração dos diferentes sub-campos acadêmicos é uma demanda atuais das políticas educacionais no Brasil. Baseado em práticas docentes que integram aspectos sociais e naturais do espaço geográfico, este trabalho objetiva apresentar uma proposta pedagógica que integra métodos e temas da Geografia Física aos da Geografia Humana a partir do estudo de bacias hidrográficas em áreas urbanas. Tal objetivo promove, ainda, a Educação Ambiental e difusão de noções dos riscos provocados pela ocupação incompatível com a dinâmica das águas em áreas urbanas.

Palavras-chave: Geografia Física,Educação ambiental; Bacias Hidrográficas Urbanas; Ensino de Geografia.

ABSTRACT The integration of different sub-academic fields is a current demand of educational policies in Brazil. Based on teaching practices that integrate social and natural aspects of geographical space, this work presents a pedagogical proposal that integrates methods and subjects of Physical and Human Geography by studying watersheds in urban areas. This objective also promotes environmental education and notions of the risks caused by disorderly occupation in relation to the dynamics of water in urban areas.

Keywords: Physical Geography, Environmental Education; Urban Watersheds; Geography Teaching 


\section{INTRODUÇÃO}

Este trabalho tem como tema demonstrar a relevância do ensino de temas relacionados àGeografia Física e da Educação Ambiental no ensino de Geografia. Para tanto, serão descritos alguns procedimentos que vêm sendo adotados no curso de Licenciatura em Geografia da Faculdade de Formação de Professores da Universidade do Estado do Rio de Janeiro (DGEO/FFP/UERJ) e que vêm contribuindo para a integração de aspectos sociais e naturais do espaço geográfico no ensino de Geografia. A metodologia proposta se baseia no diagnósticos de bacias hidrográficas em áreas urbanas, com identificação dos impactos, modos de ocupação e riscos ambientais relacionados à dinâmica das águas nessas áreas (NASCIMENTO et al. 2007; AFONSO et al., 2008; RODRIGUES \& AFONSO, 2011). Cabe destacar que este recorte temático envolve grande parte da população das regiões metropolitanas brasileiras, sendo, portanto, de grande relevância tanto no nível de ensino superior quanto no âmbito da educação básica ${ }^{1}$.

Algumas das propostas apresentadas aqui vêm sendo elaboradas há alguns anos e resultam da inquietação provocada pela percepção do desconforto que professores de Geografia têm ao tratar de temas relacionados à dinâmica da natureza no ensino fundamental e médio ${ }^{2}$. Resulta também da inquietação decorrente das discussões sobre as prioridades curriculares do ensino da Geografia, que afetaram a estruturação das grades curriculares dos cursos de Licenciatura. Trabalhos anteriores, realizados com temática e por motivos semelhantes (SOUZA, 2009;OLIVEIRA, 2010, entre outros) demonstram a relevância do entendimento dos conteúdos relacionados aos aspectos físico-naturais para contribuir para uma Geografia mais comprometida e integrada à realidade social e ambiental, capaz de estimular o desenvolvimento de habilidades e competências cognitivas e que trate das restrições e oportunidades que o meio físico representa na vida cotidiana dos alunos e professores (AFONSO et al., 2012).

\section{A NATUREZA DA GEOGRAFIA E DO TRABALHO DOS PROFESSORES DE GEOGRAFIA}

A Geografia é a ciência que estuda a dimensão espacial dos fenômenos sociais e naturais. O leque de temas que a Geografia investiga é muito abrangente, havendo diversas especialidades acadêmicas que orientam o olhar dos pesquisadores para aspectos distintos da espacialidade.

Uma pergunta frequente nos cursos de Geografia é se ela está inserida entre as Ciências Sociais ou entre as Ciências Exatas e da Terra. Esta é uma questão complexa, já que no Brasil a classificação das áreas do conhecimento é feita por órgãos como o CNPq, a CAPES e a FINEP ${ }^{3}$ A Geografia tanto aparece na grande área de Ciências Exatas e da Terra (onde aparece a Geografia Física, dentro da área de Geociências) como na de Ciências Humanas (onde está a Geografia Humana). Os cursos de graduação e pós-graduação em Geografia no Brasil possuem certa autonomia para se incluírem em uma ou outra dessas grandes áreas. Isso também acontece com os pesquisadores, que qualificam seus trabalhos conforme suas especialidades ${ }^{4}$.

Além da questão da natureza da Geografia (Física ou Humana?) está a questão da natureza do trabalho dos professores de Geografia no ensino básico. É importante que tais professores tenham conhecimento dos avanços teóricos e metodológicos gerados pelos pesquisadores nos diversos subcampos da Geografia, uma vez que esses conhecimentos tenderão a qualificar sua prática docente. E, é fato, tal integração de conhecimentos tem sido exigida aos professores de Geografia desde o nível fundamental. Isso demonstra, portanto, a importância das estratégias docentes que facilitem tal integração,bem como sua adaptação ao nível e perfil cognitivo dos alunos. 
Atualmente, segundo os Parâmetros Nacionais Curriculares (PCNs) estabelecidos pelo Ministério da Educação para o ensino básico, os professores devem estimular o desenvolvimento de procedimentos, atitudes e conhecimentos (no Ensino Fundamental) e habilidades e competências cognitivas (no Ensino Médio). Ações como observar, descrever, comparar, interpretar, analisar, compreender, avaliar, deduzir, generalizar, sintetizar e prever são exemplos dessas habilidades. Para oensino de Geografia, especificamente, os PCNsestabelecem objetivos como conhecer a organização do espaço geográfico e o funcionamento da natureza em suas múltiplas relações.

O estudo do espaço geográfico requer sua definição. Segundo Santos (2001), o espaço geográfico é constituído por "um conjunto indissociável de sistemas de objetos e sistemas de ações". Pode-se dizer que os grupos humanos se organizam (social, cultural, econômica e politicamente)sobre o meio físico, cujos elementos naturais compõem sistemas de objetos (morros, rios, praias...) e de ações (processos de encosta, fluviais, costeiros...) que constituem o espaço geográfico. Conceitos espaciais como os de paisagem, lugar, região, território, fronteira, redes e escala por exemplo, podem ser analisados a partir de categorias "miltonianas" (forma, função, estrutura, processo; fixos e fluxos) entre outras, como as categorias seletividade, técnica, diversidade, unidade, tensão, mobilidade (MOREIRA, 2001) e significado (CORRÊA, 2009). Tais conceitos e categorias são amplamente usados nos diversos sub-campos da Geografia e devem ser incorporados à prática docente dos professores em todos os níveis. Mas sob qual enfoque?

Os objetivos, conteúdos e modos de ensinar Geografia mudam com o tempo, refletindo não apenas as mudanças no espaço geográfico, mas, principalmente, as mudanças que ocorrem dentro do campo científico. Na história recente do ensino da Geografia no Brasil, percebe-se a partir da década de 1980 uma ênfase crescente na análise de processos econômicos, sociais e políticos nos livros didáticos voltados para o ensino básico. Isso se deve à consolidação das perspectivas teóricas e metodológicas relacionadas à disseminação da Geografia Crítica no Brasil, ocorrida em paralelo à redemocratização do país. Era fundamental à época levantar discussões que estimulassem os alunos à reflexão sobre como o mundo se organizava, quem eram seus agentes e instituições, que estratégias os cidadãos deveriam ter para entender e intervir em um mundo em constante mudança.

A valorização da abordagem crítica em Geografia repercutiu na produção de livros didáticos e na prática de trabalho dos professores de nível básico no Brasil. No entanto, o modo de abordar o espaço geográfico mudou apenas em parte: enquanto a sociedade, a geopolítica e a economia eram dinâmicas e discutidas a partir da perspectiva dialética, os aspectos físico-naturais permaneciam sendo descritos de modo estático, monótono, com forte apelo à memorização e fraca interação com os aspectos ditos "culturais, socioeconômicos e políticos" da Geografia. O contraste no tratamento pedagógico de temas relacionados ao "clima, relevo, rios e vegetação"era (e muitas vezes permanece sendo) desmotivador, caracterizando-se pela descrição em vez da análise de suas dinâmicas e interações.

No entanto, crescem no país as demandas sociais e políticas relacionadas à educação ambiental (Lei 9795/1999), e à disseminação de noções de prevenção contra desastres naturais (Lei 12.608/2012). Tais demandas exigem metodologias docentes mais eficientes para o ensino da dinâmica da natureza. As formas e processos dos elementos físicos são conhecimentos que devem ser aprofundados sob o enfoque da Geologia, Geomorfologia, Climatologia, Hidrologia, Biogeografia, Pedologia), cuidando para ressaltar as relações dialéticas desses elementos com os fenômenos sociais, culturais, econômicos e políticos e assim contribuir com a formação dos professores de Geografia do ensino básico. 


\section{A GEOGRAFIA FÍSICA NO ENSINO DE GEOGRAFIA}

A Geografia Física, tem como objetivo geral entender a dinâmica dos elementos da natureza e suas interações com os demais componentes do espaço geográfico. As informações produzidas por pesquisadores deste campo acadêmico refletem a demanda social e institucional por conhecimentos que promovam avanços científicos e tecnológicos relacionadas com processos naturais e seus efeitos sobre as sociedades. Um professor de Geografia será melhor capacitado se conhecer tais avanços e incorporá-los ao seu exercício docente.

O estudo dos conteúdos de Geografia Física estimulam o desenvolvimento de competências e habilidades cognitivas no Ensino Básico. Ações como observar, descrever, interpretar, comparar, estabelecer hipóteses, etc., devem serestimuladas pelos professores de Geografia desde os primeiros anos escolares e, certamente, são habilidades que podem ser desenvolvidas no ensino dos componentes curriculares ligados à dinâmica da natureza.

Os conceitos espaciais (paisagem, região, redes, escala etc.) podem (devem!) ser analisados em associação a temas relativos à Geografia Física. A incorporação de categorias geográficas (forma, processo, significado etc.) contribui na análise das formas e dinâmicas físico-naturais, incorporando em graus variados o papel dos elementos da natureza na construção geográfica das sociedades.

Outra justificativa para uma sólida inclusão de temas relacionados à dinâmica da Natureza nos cursos de ensino básico e de licenciatura em Geografia tem a ver com a divulgação de mecanismos de prevenção, mitigação e preparação contra riscos naturais. O homem, como ser social, cria novas situações ao construir e reordenar os espaços físicos segundo suas necessidades, competências e interesses. Ross (2006) ressalta as múltiplas interferências da sociedade sobre a dinâmica dos ambientes naturais quando afirma que as unidades de paisagens naturais são também resultado das interferências antrópicas.

Os professores de Geografia possuem um papel importante na disseminação de informações relativas ao modo como as sociedades devem interagir com a dinâmica ambiental de forma segura e sustentável. A análise dos processos climáticos e geomorfológicos, por exemplo, possibilita a prevenção, mitigação e preparação contra riscos de enxurradas, enchentes ou desmoronamentos de encostas, contribuindo para evitar as perdas humanas e prejuízos materiais deles decorrentes. Tais conhecimentos estimulam a possibilidade de ação social e política mais consistente, fortalecendo posturas mais críticas em relação à ocupação do solo e expansão urbana.

Entender melhor a dinâmica dos componentes da natureza (e das suas relações com as sociedades) amplia o acervo conceitual dos educandos, estimula atitudes ambientalmente menos impactantes (e mais seguras) e contribui para o a ampliação de possibilidades e perspectivas do cidadão em formação. Esses três objetivos devem estar claros e presentes no cotidiano dos professores de Geografia, ratificando a sua interação crítica com meio em que vive.

\section{EDUCAÇÃO AMBIENTAL NO BRASIL E O ENSINO DE GEOGRAFIA}

O desconhecimento das dinâmicas no meio físico e o despreparo para enfrentar as consequências advindas das relações entre sociedade e natureza agravaram a crise ambiental no Brasil e no mundo nas últimas décadas. Nos últimos 50 anos, eventos marcantes contribuíram para sustentar ações políticas cada vez mais estruturadas em relação à problemática ambiental. O caráter político do movimento ecologista nos países mais industrializados se configurou mais claramente por volta dos anos 1960, tendo em vista o expressivo nível de degradação (sócio) ambiental. A dimensão e visibilidade das reivindicações ambientais se disseminaram no plano internacional rapidamente, 
chegando fortemente ao Brasil nos anos 1980. A pressão do movimento ambientalista internacional e interno levou à inclusão de um capítulo sobre o meio ambiente na Constituição Brasileira de 1988.

A expansão dos fóruns de discussão dos problemas ambientais demonstra a urgência em compreender a dinâmica ambiental e sua relação com os modelos de desenvolvimento urbanoindustriais, incluindo padrões culturais, relações sócio-econômicas entre países, classes sociais e categorias produtivas. Nesse contexto, aEducação Ambiental (EA) vem se consolidando como reivindicação da sociedade em geral. Tal demanda levou à sua consolidação como campo científico, o que exigiu reflexões de caráter teórico e metodológico a fim de situar essa prática docente.

As disputas entre os muitos agentes e suas concepções em torno da questão ambiental torna a EA um campo tão vasto quanto polêmico. Aqueles que buscam nele atuar devem saber que são muitas as estratégias de abordar o tema, metodologias de trabalho, práticas pedagógicas e/ou políticas, que variam conforme as concepções de Natureza, Ambiente e mesmo de Educação dos envolvidos.

Loureiro et al. (2009) reconhecem três perspectivas teórico-filosóficas de maior influência no Brasil (e alguns de seus principais representantes acadêmicos): a marxista (representada por Carlos Frederico Loureiro, Carlos Walter Porto Gonçalves), a fenomenológica (Michele Sato) e a hermenêutica (Isabel Carvalho, Marcos Reigota). Do ponto de vista metodológico, Carvalho (2008) aponta duas diretrizes que orientam as estratégias docentes de EA:

1) a perspectiva comportamental, que enfatiza a realização de atividades práticas para mitigar ou resolver problemas ambientais, tais como coleta seletiva e reciclagem de lixo, consumo 'racional' de água e de energia, reflorestamento, plantio de hortas, proteção de mananciais etc.;

2) a perspectiva atitudinal, que prioriza discutir sociedade, ética e cidadania, incluindo o questionamento de modelos de produção e consumo, exploração socioeconômica, riscos e vulnerabilidade socioambientais, conflitos entre interesses privados e bens públicos, modelos de sustentabilidade social e ambiental. A perspectiva atitudinal tem objetivos mais abrangentes e radicais, pois sugere transformar a sociedade, revertendo o quadro de degradação socioambiental a partir de atores políticos sensibilizados e mobilizados pela causa ambiental.

Atualmente, as políticas públicas de EA vêm sendo construídas no MMA e MEC - ministérios do Meio Ambiente (EA não-formal, a ser implementada por empresas públicas e privadas, organizações não-governamentais etc.) e Ministério da Educação (EA formal, escolar). A lei federal 9394/96 de Diretrizes e Bases da Educação Nacional (LDB) estipula que a EA formal deva ser promovida em todos os níveis de ensino. A lei sugere que o tema "Meio Ambiente" seja tratado de modotransversal, considerando "os aspectos sociais, econômicos, científicos, tecnológicos, culturais, ecológicos e éticos" a fim de possibilitar uma visão integrada do ambiente da escala global à local (PEDRINI, 2004). A Lei N 9.795/1999 de Política Nacional de Educação Ambiental(PNEA), institui a obrigatoriedade da EA em todos os níveis de ensino. A sugestão é de que isso seja feito como uma prática educativa integrada, sem necessariamente a inclusão de uma disciplina de EA no currículo do Ensino Básico. Permanece, no entanto, a possibilidade da EA constar como disciplina no ensino superior em situações específicas.

Proposta para entrar no programa escolar como tema transversal de caráter interdisciplinar, a Educação Ambiental (EA) não está inserida formalmente na carga horária de nenhuma disciplina e tampouco há parâmetros metodológicos e teóricos que orientem a prática docente. Se isso cria dificuldades, também abre oportunidades: a rigidez dos currículos oficiais não é tão grande que impeça o aproveitamento do enorme volume e diversidade de informações disponíveis sobre o tema. A EA tem papel de destaque na conscientização para um melhor uso dos recursos naturais disponíveis no meio ambiente. As instituições de ensino devem estimular a análise das informações relativas à 
dinâmica da natureza (dos canais fluviais, encostas, áreas costeiras etc.) e sua interação com a dinâmica sócio-econômica, cultural e produtiva estabelecida.

Há muitos professores de Geografia que abordam temas e processos ambientais de modo muito superficial, sendo frequente a reprodução de chavões divulgados pela mídia de massas. Tal despreparo resulta em parte do desconhecimento teórico-metodológico, agravado pela negligência ou ineficiência com que se tratam as questões da dinâmica da natureza. Esse quadro é em parte consequência dos questionamentos quanto à necessidade de aprofundamento de conteúdos relativos à Geografia Física nos currículos de licenciatura em Geografia.

Diante da necessidade de compreensão de um mundo no qual a questão ambiental é crítica, é fundamental que se criem pontes que contribuam para a transdisciplinaridade entre conhecimentos produzidos por diferentes áreas do conhecimento, superando a dicotomia existente entre as abordagens estritamente sociais ou naturais. Nesta perspectiva, as dinâmicas do meio físico (clima, relevo, biomas etc.) e socioeconômico (aspectos da cultura, da política e da produção e circulação de bens e serviços) estão tão integradas que superam o sentido da divisão de temas entre Geografia Física e Humana. Tal integração representa um recurso metodológico à docência em Geografia e consolida a ação do professor como aquele que estimula o educando a buscar os recursos analíticos capazes de levá-lo a uma compreensão mais articulada e menos compartimentada da realidade.

Acreditando que os princípios educativos devam primar pelo caráter crítico acerca da produção do espaço, venho buscando a prática docente que incorpore a compreensão mais abrangente de que as sociedades estão sobre um mundo composto de elementos naturais, em constante processo de ajuste (AFONSO \& ARMOND, 2009). Deve-se compreender a relação entre a sociedade e a natureza enquanto algo dialético, onde o homem transforma a natureza ao mesmo tempo em que sofre suas influências e respostas (ARMOND \& AFONSO, 2010).

\section{ESTUDO DE BACIAS HIDROGRÁFICAS EM ÁREAS URBANIZADAS NA LICENCIATURA EM GEOGRAFIA}

Ao seguir seu percurso, as águas refletem as condições naturais e as atividades antrópicas desenvolvidas nas bacias hidrográficas. Em todo o mundo, a expansão de cultivos e de áreas urbanoindustriais se deu sem grandes preocupações com os recursos hídricos ou com as redes hidrográficas, tendo por premissa que a água seria um recurso renovável e infinito. Premissa falsa: o ciclo hidrológico não disponibiliza água potável no mesmo ritmo da expansão mundial da demanda.

A bacia hidrográfica como unidade de análise espacial, permite reconhecer as relações existentes entre os elementos que constituem a paisagem e os processos que atuam na sua estruturação. Trata-se de uma unidade espacial adequada ao planejamento de uso e ocupação do solo (BOTELHO, 2007) e à gestão de recursos hídricos: nela interagem fatores biológicos, físicos e sócio econômicos. Mudanças em qualquer desses fatores podem gerar alterações no meio físico como um todo (COSTA, 2001; CUNHA 2008).

As bacias hidrográficas em áreas urbanas têm seus rios extremamente modificados pela poluição das águas por esgotos, aterros e intervenções que comprometem tanto a qualidade das águas como a dinâmica fluvial. A urbanização modifica o comportamento do ciclo hidrológico, impactando a trajetória e dinâmica dos fluxos superficiais e subsuperficiais da água. A construção de galerias subterrâneas de escoamento de águas pluviais e fluviais promove tal descaracterização do meio físico em áreas urbanas que leva até mesmo ao desconhecimento da existência da rede hidrográfica (subterrânea) pela população local.

Os rios alterados pela urbanização desordenada possuem mecanismos de ajuste diante de eventos de chuvas extremas que podem provocar fenômenos de alto risco para a população em áreas 
sujeitas a enchentes. A ineficácia de políticas de planejamento urbano e o paradigma (muito questionado) de obras de engenharia (canalizar cursos d'água, por exemplo) levam, comumente, à intensificação dos riscos relacionados ainundações.

Na Região Metropolitana do Rio de Janeiro, a dinâmica das águas nos canais fluviais foi e é tremendamente alterada pelo uso das margens dos rios para edificação de moradias e pela impermeabilização de boa parte dos solos, devido ao alto grau de urbanização. Tal fato proporciona impactos diretos nas bacias de drenagem e consequentemente nos canais fluviais, contribuindo para o agravamento de eventos extremos, principalmente, as enchentes e inundações, que atinge grande parte dos municípios da região metropolitana no período de verão, onde a ocorrência de chuvas torrenciais no fim das tardes torna-se mais frequente.

A mídia (em alguns casos) apresenta eventos como enchentes e enxurradas sob a lógica sensacionalista, onde o ambiente não é visto como resultado de processos dinâmicos de evolução da paisagem, mas sim como um algo desarticulado do sistema geomórfico em que está inserido. Eventos extremos fazem parte da dinâmica hidrológica de bacias hidrográficas, ou seja, são fenômenos naturais. No entanto, por serem processos de alta intensidade, mas pouco recorrentes, não são levados em consideração durante o processo de expansão urbana, frequentemente incompatíveis com a dinâmica dos elementos naturais. Os professores de Geografia e educadores ambientais de modo geral devem alertar seus alunos para este tema a fim de contribuir para a divulgação de informações sobre os riscos da gestão inadequada dos rios e bacias hidrográficas em áreas urbanas.

Os métodos de investigação e de interpretação de informações propostos para a análise de bacias hidrográficas em áreas urbanas integram os componentes naturais, sócio-econômicos, culturais e políticos do espaço, a partir do conceito de complexidade (MORIN, 2006), da perspectivasgeossistêmica (CHRISTOFOLETTI, 1999), socioambiental (MENDONÇA, 2001) e histórico-ambiental (FREITAS, 2002). Tal metodologia vem sendo empregada em trabalhos de alunos da Licenciatura do DGEO/FFP/UERJna análise dos principais impactos e alterações em diversas bacias hidrográficas na Região Metropolitana do Rio de Janeiro. Tais trabalhos vêm contribuindo para a sensibilização dos licenciandos para as complexas relações entre gestão do espaço urbano, recursos hídricos, responsabilidade socioambiental e demandas políticas. Basicamente o trabalho proposto inclui cinco etapas:

a) Levantamento de informações bibliográficas sobre bacias hidrográficas e dinâmica hidrológica em áreas urbanas, priorizando os fatores relacionados à ocorrência de enchentes, poluição de águas e alterações nos regimes fluviométricos de canais fluviais;

b) Identificação das redes hidrográficas próximas às áreas de estudo ou moradia dos aluno a fim de estabelecer o estudo na escala do local, do espaço vivido (supostamente melhor conhecido);

c) Levantamento e análise de imagens satélites obtidas pelo software livre "Google Earth" ${ }^{T M}$ e cartas topográficas para análise com vistas a identificar e delimitar as bacias hidrográficas na área selecionada;

d) Percorrer trechos da bacia hidrográfica para uma análise da distribuição espacial dos usos do solo, identificação, avaliação e mapeamento dos problemas mais críticos e agentes responsáveis pela degradação do ambiente fluvial urbano (com registro fotográfico ou em vídeo).

e) Produção de relatório e divulgação de resultados.

Tais procedimentos viabilizaram uma abordagem mais concreta e objetiva da dinâmica fluvial, bem como permitiu otimizar um recurso cartográfico facilmente disponível como as imagens do "Google Earth" (LIMA, 2012). A estratégia de levar os educandos a conhecer melhor as bacias hidrográficas próximas a suas residências ou escolas tem relação com a dimensão atitudinal da educação ambiental. Ao percorrer trechos ao longo dos canais fluviais, identificando aspectos comprometedores da dinâmica dos rios, as ações antrópicas responsáveis pela degradação das águas,

Rev. Tamoios, São Gonçalo (RJ), ano 09, n. 1, pags 76-85, jan/jun. 2013 
proliferação de organismos patogênicos e intervenções de engenharia inadequadas (agravadora de enchentes), ocorre a percepção de que as águas no meio urbano não são objeto de gestão adequada.

O processo de descoberta e análise da problemática das águas na escala local estimula a reflexão dos educandos sobre a sua experiência cotidiana com o lugar habitado, interligando-a às informações teóricas obtidas através do saber acadêmico. Taisdiscussões têm, ainda, ampliado a compreensão e a mobilização de diversos alunos para a questão da integração de aspectos sociais e naturais na gestão urbana de recursos hídricos, políticas de habitação, transportes e saneamento básico na Região Metropolitana do Rio de Janeiro, sendo portanto, uma estratégia docente muito instigante.

A objetividade e simplicidade com que os temas e conceitos acadêmicos são abordados na prática pedagógica contribuem para que o conjunto de procedimentos sugeridos seja aplicável a outras áreas de estudo por profissionais interessados em atuar no campo da EA, podendo também ser utilizado em cursos de extensão universitária, palestras para comunidades sujeitas a riscos ambientais etc.

\section{CONSIDERAÇÕES FINAIS}

As contribuições teórico-metodológicas da Geografia Física e da Educação Ambiental têm sido reconhecidas como capazes de mobilizar transformações culturais, sociais e institucionais através da compreensão das relações entre natureza e sociedade. A aplicação dos conhecimentos relativos aos elementos da Natureza - relevo, drenagem, solos, clima, biomas etc. - na vida cotidiana tem profunda relação com oportunidades e/ou restrições que podem influenciar a vida de alunos e professores. Tal compreensão pode ser um estímulo à adoção de atitudes ambientalmente desejáveis e mais seguras.

Toda ética e toda noção de cidadania pressupõem um conjunto de comportamentos pró-ativos mas também algumas restrições a que nos submetemos em nome de algo maior ou de uma coletividade. Por um lado, a ética ambiental pode exigir mudanças no sentido de restringir padrões de consumo, exigir cuidados com dejetos e efluentes, limitar a expansão de áreas edificadas e cultivadas a fim de preservar águas, biodiversidade, ar e solos. Por outro lado, a sustentabilidade ambiental pode estar associada a benefícios sociais imediatos, como redução de riscos sociais e melhorias na qualidade de vida.

Fica, portanto, a recomendação de que professores de Geografia em geral reconheçam tanto a importância de integrar conceitos e categorias geográficas à análise de temas ambientais como a de inserir os conhecimentos relativos à dinâmica da natureza em todos os níveis de ensino.

\section{NOTAS}

1- No Brasil, a educação básica ocorre ao longo de doze anos, sendo os nove primeiros enquadrados como ensino fundamental e os três seguintes, como ensino médio.

2- Tais afirmativas são feitas a partir de experiências pessoais como docente nas redes de ensino público e particular da Região Metropolitana do Rio de Janeiro, tanto no ensino básico como no superior.

3- CNPq,CAPES e FINEP são órgãos responsáveis pelo estímulo ao desenvolvimento científico, tecnológico, cultural e profissional no Brasil. O CNPq é uma agência do Ministério da Ciência e Tecnologia destinada ao fomento da pesquisa científica e tecnológica e à formação de recursos humanos para pesquisa no país. A CAPES é uma fundação do Ministério da Educação voltada para a formação de recursos humanos de alto nível em todas as áreas do conhecimento. A 
FINEP é uma empresa pública vinculada ao Ministério de Ciência e Tecnologia e objetiva financiar a expansão do sistema de ciência e tecnologia no Brasil.

4- A proposta recente de colocar todas as especialidades da Geografia dentro da grande área de Ciências Humanas causa bastante polêmica, seja pela questão das diferenças metodológicas e epistemológicas entre pesquisadores das duas áreas, seja pela questão da política nacional de distribuição de recursos entre as áreas do conhecimento.

\section{REFERÊNCIAS BIBLIOGRÁFICAS}

AFONSO, Anice; RODRIGUES, Felipe; ARMOND, Nubia; BRANDÃO, Rafael; MORELLI, Rafaela. Análise da dinâmica fluvial do rio Imboacu (São Gonçalo, RJ): um enfoque a partir da consciência ambiental. In: Anais do II Simpósio de Recursos Hídricos do Sul-Sudeste. Rio de Janeiro. 2008.

AFONSO, Anice; ARAÚJO, Jefferson; SILVA, Juliano; SILVA, Aline; ROSA, André. Possibilidades para o ensino e aprendizagem em Geografia Física. Anais do XVII ENG, Belo Horizonte. 2012.

AFONSO, Anice; ARMOND, Nubia B. Reflexões Sobre o Ensino de Geografia Física no Ensino Fundamental e Médio. In: X Encontro Nacional Prática de Ensino em Geografia, Porto Alegre, 2009.

ARMOND, Nubia \& AFONSO, AniceDa Geografia Física à Geografia (sócio) ambiental e seu "retorno" à Geografia: breves reflexões sobre mutações epistemológicas e o campo científico. In: Anais do XVI ENG, Porto Alegre, 2010.

BOTELHO, Rosangela G. Planejamento Ambiental em Microbacia Hidrográfica. In: GUERRA, Antonio Teixeira; SILVA, Antônio; BOTELHO, Rosangela (Orgs.). Erosão e Conservação dos Solos: conceitos, temas e aplicações. $3^{\mathrm{a}}$ ed. Rio de Janeiro: Editora Bertrand Brasil, 2007.

CARVALHO, Isabel C. Educação Ambiental: a formação do sujeito ecológico. $3^{\mathrm{a}}$ edição. 256 pp. São Paulo. Ed. Cortez. 2008.

COSTA, Heinrich. Enchentes no Estado do Rio de Janeiro: uma abordagem geral. Rio de Janeiro: SEMADS, 2001.

CHRISTOFOLETI, Antônio. Modelagem de Sistemas Ambientais. São Paulo, Ed. Edgard Blücher. 1999.

CORRÊA, Roberto Lobato. Processo, forma e significado- uma breve consideração. Publicado no site do Instituto Histórico e Geográfico do Rio Grande do Sul em 10/11/2009 e disponível em http://www.ihgrgs.org.br/Contribuicoes/Processo_Forma_Significado.htm

CUNHA, Sandra. Canais Fluviais e a Questão Ambiental. In: CUNHA, Sandra. \& GUERRA, Antônio. (Orgs.). A Questão Ambiental. $4^{\mathrm{a}}$ ed. p. 219-238. Rio de Janeiro. Ed. Bertrand Brasil, 2008.

FREITAS, Inês. A Geografia na construção de uma História Ambiental brasileira. Boletim Goiano de Geografia, c. p. 155-168. Vol.22,n.2, 2002. 
LIMA, Raphael. Google Earth aplicado a pesquisa e ensino da Geomorfologia. Revista de Ensino de Geografia, v. 3, n. 5, p. 17-30, Uberlândia. 2012.

LOUREIRO, Carlos;TREIN, Eunice; TOZONI-REIS, Marília.; NOVICKI, Victor. Contribuições da Teoria Marxista para a Educação Ambiental Crítica. Cad. Cedes, Campinas, vol. 29, n. 77, p. 81-97, 2009.

MENDONÇA, Francisco. Geografia Socioambiental. Terra Livre, n.16, p.113-132, São Paulo, 2001.

MOREIRA, Rui. As categorias espaciais da construção geográfica das sociedades. GEOgrafia. Niterói: volume $3, n^{\circ}$ 5, 2001

MORIN, Edgar. O método. V. 6 - Ética. Porto Alegre, Ed.Sulina 2006.

NASCIMENTO, Julliana; ROSÁRIO, Luana; AFONSO, Anice; BARROS, Rafael. A utilização do programa Google Earth na Educação Ambiental: uma experiência na bacia do rio Marimbondo - São Gonçalo/RJ. XXIII CongressoBras. de Cartografia, p.1259- 1263. Rio de Janeiro. 2007

OLIVEIRA, Adriana Sposito. Contribuição teórico-metodológica para o ensino da Geomorfologia. Tese de Doutorado. UNESP Presidente Prudente. 2010

PEDRINI, Alexandre. As Políticas Públicas Nacionais com Educação Ambiental no Brasil: evolução e perspectivas. In: AZEITEIRO, U., GONÇALVES, F \& PEREIRA. M. (Eds) Alemanha, Peter Lang Ed., 2004. Disponível em http://www.cpd1.ufmt.br/gpea/pub/pedrini_pp_ea.pdf

RODRIGUES, Jorge; AFONSO, Anice. Relações entre padrões de uso do solo enchentes ao longo dos canais fluviais da bacia hidrográfica do rio Caceribu, Tanguá (RJ). XIV Simpósio Bras. de Geogr. Física Aplicada, Dourados, MS. 2011.

ROSS, Jurandyr. Ecogeografia do Brasil: subsídios para planejamento ambiental. São Paulo: Oficina de Textos, 2006.

SANTOS, Milton. A Natureza do Espaço: Técnica e Tempo, Razão e Emoção. $4^{\mathrm{a}}$ ed. São Paulo. EdUSP. 2001.

SOUZA, Carla. Geomorfologia no ensino superior: difícil, mas interessante! Tese de Doutorado. Belo Horizonte. UFMG. 2009. 